\title{
The Therapeutic Status in the Integrative Strategic Model of Supervision
}

\section{Geamanu Anisoara}

Association of Integrative Research, Counselling and Psychotherapy, Bucharest, Romania

\section{Email address:}

anisoara.geamanu@yahoo.com

\section{To cite this article:}

Geamănu Anişoara. The Therapeutic Status in the Integrative Strategic Model of Supervision. International Journal of Neurologic Physical Therapy. Vol. 5, No. 1, 2019, pp. 5-12. doi: 10.11648/j.ijnpt.20190501.12

Received: May 5, 2019; Accepted: June 2, 2019; Published: June 12, 2019

\begin{abstract}
The paper presented was conceived as a result of difficulties met at the beginning of the psychotherapy career, during supervision. The therapeutic status, used in the study presented, is a document of great importance in the training of the future psychotherapist according to the integrative strategic model of the self conceived by the authors Loredana-Ileana Viscu and Oana-Maria Popescu, in Romania. This model is briefly described in order to better understand the use of instrumentsduring the supervision process. The case of C. M. is also presented in order to better underline the practical application of the instrument mentioned.
\end{abstract}

Keywords: Psychotherapeutic Status, Integrative Strategic Model, Supervision, Psychotherapy

\section{Introduction}

The realisation of information processing actions, the psychotherapy action realised in a private office is considered a complex one, because it supposes an important analysis of the client and later a self-analysis (phenomenological) of the psychotherapist.

Even if the integrative strategic model of the self (proposed by Vîşcu L. I. and Popescu O. M) was well acquired and studied during training years, a transposition of the therapy session into words was still difficult, as was the conceiving of a therapeutic status. [1-3]

A psychotherapy session exposure in status, the manner in which problems met with the client are presented, the therapist's phenomenological process, transposed according to the integrative strategic model of supervision seems easy to sketch and present for a psychotherapist in supervision. [4] It refers to personalized aspects, unique for each of us, it presents therapists as individuals, vulnerable and exposed and reflects the evolution stage in the psychotherapeutic field from a theoretical and especially, from a practical point of view. The beginner psychotherapist's concerns are registered and analyzed in supervision with the help of this supervision model and the instruments proposed. [5]

As the usefulness of this instrument is obvious, the explaining of some theoretical aspects and the practical exemplification of some instruments seem to be necessary for those found at the beginning of their careers.

The case study presented, of the statuses included, were realized according to the integrative strategic model of the self, proposed by Viscu Loredana-Ileana and by Popescu Oana-Maria. [1-3] This model approaches the self on four domains (the basic self, the central self, the plastic self and the external self), being analysed on six psychological axes: Biological (B), Cognitive (C), Emotional (A), Psychodynamic (P), Existential (E) and Familial (F). [3] The client's potential is underlined in the diagnosis received. [6]

\subsection{Integrative Strategic Psychotherapy}

The history of integrative strategic psychotherapy starts from the basis of its evolution, crossing and acquiring the essence of theoretical and practical psychotherapy borders, from different orientations, being an emergent "living" orientation, continuously changing and developing. [7] It is sustained by a complex theoretical system and by an integrative strategic model of the self, where the key element is the psychotherapeutic relation. [8]

Specialty literature underlines a recent history of the integrative strategic psychotherapy, which started at the end of the $20^{\text {th }}$ century, with the publication of the first integrative model proposed by

Norcross and Goldfried in 1992. This trial to integrate 
psychotherapy, to structure and consolidate a new orientation received help from important representatives in the domain: Thomas French (1932), Rosenzwig (1936), Dollard \& Miller (1950), Frank \& Frank (1961), Lazarus (1967), Erskine (1972), Goldfried and Newman (1996), Butler-Bowdon (2009) Gilbert, Orlans (2013), Wachtel (1977), Hawkins \& Nestoros, Consoli \& Lane, Beautler, Norcross and Goldfried, Prochaska \& DiClemente and others. [2]

In Romania, the integrative strategic psychotherapeutic orientation can be analysed, studied and learnt inside the Association of Integrative Research, Counselling and Psychotherapy, accredited by the Romanian Association of Psychotherapy, by the European Association for Integrative Psychotherapy (EAIP), and by other similar professional system, national and international, offering a large diversity of approaches, theoretical and practical resources efficiently applied in psychotherapy. [3]

\subsection{Integrative Strategic Model of the Self}

The integrative strategic model of the self, proposed by Vîşcu and Popescu, specific to integrative strategic psychotherapy, is an inedited vision of the self, considered as being built of four large domains (the basic self, the central self, the plastic self and the external self), being analysed on six psychological axes, which are in fact "slices" of one's self or "parts of a global hologram of the self". [3] This model "integrates more important psychotherapy theories in a unitary frame based on research in the neurobiology and attachment domains" and "it takes into consideration a multitude of variables, from the biological ones to the transpersonal ones." [3]

The basic self, constructed since the early childhood at a non- and pre-verbal level, at a neurobiological level, is build of structures of the brain containing the first internal working models (IWM), the first neuronal paths "crucibles" "waiting" for experiences from the internal and the external environments. [9]

The central self, develops during childhood processes nonverbal and verbal information, containing "central sets" translated into a series of mental models of schemas.

The plastic self refers to internal causality and to maintenance mechanisms of "central sets" through internal loops of feedback.

The external self represents the interface between the individual and his/her external environment and reflects in visible behaviours, which can be perceived through an experience of the self as "here and now", as a result of the impact of stimuli from the internal environment and from the surrounding environment. $[1,10]$

The six psychological axes refer to different manner in which the self is built, being in fact sections, "slices" of the self or "parts of a global hologram of the self". [1, 10]

This integrative strategic model is better explained by transposing it in the psychotherapeutic status presented in this paper.

\subsection{Supervision Model in Integrative Strategic Psychotherapy}

The integrative strategic model of supervision, proposed by the same authors, Loredana-Ileana Vîșcu and Oana Maria Popescu, is well anchored in the unification theory of integrative psychotherapy and resulted from a rich experience in the psychotherapy office and from a phenomenological approach of essential aspects of psychotherapy, being at the same time instructive, practical and difficult to explain in works. [4]

This model, considered a part of the second generation of supervision models, is a relational one containing the following elements (common factors in integrative psychotherapy): learning in supervision, supervision framework/ learning space, factors that influence learning in supervision and reflection on the case. [4]

For the supervisee, learning starts and continues once he/she decides to train in psychotherapy, to start personal development and later the supervision process, which supposes the existence of a dynamic and complex phenomenon, of permanent and definite change of personality aspects, which sustain a professional behaviour in psychotherapy. [11, 12]

The supervision frame contains the learning space, cocreated by the supervisor and the supervisee, together with other essential elements: supervision space, what becomes familiar in time; the supervision contract, a document signed at the beginning of the supervision period, containing objectives proposed and accepted by both parts, accentuating the reciprocity of both factors involved; the supervision alliance, which is collaborative-participative, non-punitive, supportive, and encouraging for the supervisee. [11]

Factors influencing learning are common factors in supervision: the supervisor's style, the supervisee's style, the context of their work, the supervisee's relational and learning needs, learning styles and the supervisee's education, monitoring and evaluation in supervision. [8]

Reflecting on a case, supposed the existence of a client file which contains: the psychotherapy/counselling contract signed by the supervisee and his/her client, a document standing at the base of an involvement in the therapeutic process between the two actors and which insures a written support in case of problems, legal fights, that involve judicial organisms or superior authorities; an informed consent, which may also be contained by the contract, if it is demanded by the therapist to persons involved in the therapeutic process; the psychotherapeutic status, realized by the therapist for each session with the client, a mirror of his/her work; the psychodiagnostic interview, a sketch of intervention in the psychotherapist's practice; supervision sheets, which synthesizethe supervisee's activity and which can also be introduced in the client's file. [12]

Supervision can be realized in different manners: individual or in groups (formed according to specific criteria), online (visual), on the phone etc. Face-to-face supervision seems to be the most efficient one, but the group 
sessions are as productive, even if these are less recommended, because in cases of "emergency" problems, difficulties met during therapy demand time to solve. [4]

\section{The Psychotherapeutic Status - Theoretical Presentation}

Specialty literature offers some theoretical aspects regarding the psychotherapeutic status, which is a documents "mirroring" the client session and which, in essence, represents a synthesis of data regarding: client information, data regarding psychotherapeutic objectives established together with the client, intervention methods and techniques, therapist's observations and proposals for the client and for certain therapy parts, information on the improvement of the psychotherapeutic relation, the psychotherapist's selfanalysis and other important information. This document must be filled in after each psychotherapy session or may be partly filled in, with the client's approval during the session, according to the case. [12]

The psychotherapeutic status is filled in by the novice psychotherapist, undergoing the supervision process for his/her professional evolution or by any independent professional. The difference for the experiences psychotherapist is that the client's file may contain only the psychotherapeutic status for the first therapy session and for a few relevant sessions and maybe, for the final working session with the client.

Its component elements, sustaining the structure of a psychotherapeutic status, are:

a. The psychotherapist's, the client's identification data, the number and date of the session and the date of an initial interview;

b. A structured diagnosis with the symptoms presented by the client in connection with aspects of his/her personality (the disorder clinical image or any other symptoms identified, the seriousness of these symptoms from slight to serious, somatisations, the client's personal resources, his/her social and environment resources);

c. The process diagnosis, on the self domains and on the client's affected psychological axes, according to the integrative strategic model of the self, the establishment of general objectives with the client and of specific objectives for each therapy session and the of other sessions with the client;

d. Recommendations for the psychotherapeutic treatment, regarding supplementary somatic, psychiatric, clinical and hospitalisation examinations for the client and other information regarding psychotherapy: the estimation of the treatment duration, session frequency, type of psychotherapy recommended, financing etc.;

e. The psychotherapeutic intervention, with the description of the session, on the axes worked on, on the objectives proposed to be fulfilled on those axes, methods and techniques used to reach those objectives, the description of the client's behaviour during his/her first visit to the office, the identification of the client's insights, if these situations appeared, and any changes observed in the client's behaviour;

f. Any homework given to the client and encouragements used with the client to obtain a behavioural change;

g. The description of the psychotherapeutic session: the therapist's reflection on aspects regarding the building of a therapeutic alliance and relation, the existence of possible moments of relation "rupture", the therapist's perception of the client in therapy and the time spent with the client, the client's needs, his/her attachment style manifested in the therapeutic relation, the therapist's proposals for the improvement of the psychotherapeutic relation. [12]

The benefit offered by the filling in of this document is observed in the exercise of the beginner psychotherapist's aptitudes regarding data synthesis, case conceptualisation and the understanding of the therapy essence. It also helps in the cultivating and developing of the therapist's specific thinking on certain cases, filtered through the integrative strategic model of the self, thus leading to the cultivating and maintaining of a divergent and complex thinking manner, to the maintaining of an organised and efficient working method and to a correct attitude towards him/herself and the activity with the client.

Specialists in the domain sustain that "a psychotherapeutic status, maintained during the first years of the psychotherapist's professional exercise and after the graduating of a supervision process, represents the mirror of the therapist's work in the psychotherapy office; it demands attention, scientific rigorousness, continuous study; a rigorous reflection on the case; it insures the becoming aware of the intervision and supervision need; it allows the therapist's cultivation of an appropriate and flexible style; it supposed the manifest of a respect for the client". [4]

The first supervision session in psychotherapy - whether it is group supervision or an individual session - is an event for the supervisee, so the beginner therapist needs proper instruments to help him in therapy with the client. [13]

The supervision process is realized according to a framework established according to different psychotherapeutic orientations and in the case presented below, the integrative strategic model of the self, offers a therapy framework and even a supervision model, that is meant to help the beginner therapist and the supervisee, during the complex process of therapy with the client and of supervision with a supervisor. [14]

\section{Case Study: C. M}

\subsection{Case Presentation}

The client C. M., 30 years old, has been married for 9 years with A., has an 8 years old boy, who is a pupil in the second grade. The client has graduated high school and is employed in a supermarket from the locality. The family 
income seems be sufficient, because his wife also works and they receive financial help from the family. They live in a town, in a house owned by the maternal grandmother, who also has a building in the same yard. C. came to therapy accompanied by his mother (M.), who also established the appointment with the client's agreements and at the recommendation of a colleague psychologist.

His problems, as presented by the mother in his presence and confirmed by the client, began 5 years earlier, when he used to gamble and invest in "pacanele" and in "sports bets", and when intermittent period of compulsive gambling were observed.

The situation is presented as critical for C. and his nuclear family. From a financial and material point of view the client faced bankruptcy: the client made large loans, his house was taken by the creditor bank; he stole gold and silver jewellery from the family; he stole goods from the house; he pawned mobile phones etc. in order to obtain necessary money for gambling.

He was also facing a loss of his job because of long absences from his working place and from a relational point of view he faced divorce and the loss of his son, the loss of relations with friends, accountancies, colleagues, neighbours, which he owed money. From a family point of view, he lost all support, financial and material. All these problems resulted from an addictive-compulsive gambling.

The mother sustains that he is a pathological liar, an emotional blackmailer and a manipulative person, and that he changed so much that now one recognized him anymore. He started consuming moderate quantities of alcohol, but rarely got drunk. He smoked 2-3 packs of cigarettes every day.

After a few talks with her son (having a close relation) they decided to get specialized help, because the client tried on different occasions to cure his addiction but results were for short periods of time. He came accompanied to the office so that the mother would be convinced he came and that he didn't have access to large amounts of money, the session being paid by the mother with the client's credit card.

From her words some aspects of C. past resulted: the pregnancy was normal, the child was born in time, he had childhood diseases; his physical and psychic development was normal, he was raised by his maternal grandparents in the same house he now lived in. C. lost his biological father at the age of 5, when his parents divorced because his father was also a gambler (as his paternal uncle) who gradually became an alcoholic (as the client's paternal grandfather), family relations being destroyed, the father had many unpaid financial debts and died "a street vagabond" when C. was 17 years old.

The client was left in the maternal grandparents care since his birth, and the mother remarried when he was 11 years old, when he went to live with his mother, and where, after 4 years his step brother was born. The mother felt guilt and tried to compensate it by spoiling both boys. C. was a good pupil, who didn't create problems, but he was isolated and didn't communicate. The mother sustained that he loved his biological father, but didn't have enough time to know him better. He considered the son a "living continuity" of the father who "looked like him and acted like him", said the mother with pride and pain.

C. practices boxing during his adolescent period and manifested physical aggressiveness only when found in danger or when his family was in danger. He never started a quarrel or a fight.

The client presented as being well dressed, in sports clothes specific to adolescents, fit to his body, with lots of writing and colours on his clothes. He has an athletic body, a medium height; he is robust, with strong hands. His posture seems slightlybent; his face is common and nice, even if he keeps looking down. He avoids visual contact, but realized it while taking. He shows calming gestures, he caresses his head with his hands and covers it with his arms and hands as trying to protect it from getting hit. He rubs his hands and feet, massages his fists and constantlychews his nails. In the office he is inconstantly restless, agitated, absent, curious, bored, silent, thinking and difficult in communicating. He justifies all his actions by being shy, even if he doesn't seem to be, that he feels discomfort when meeting someone and when he is the centre of attention, because he doesn't like to talk.

From the first discussions contained by the psychotherapeutic interview, a desperate young man came out, overwhelmed by all aspects of his life, but smart, immature, curious, sceptical, introvert, neurotic and little communicative. He is confident that he will manage to solve his problems. He agreed in starting psychotherapy, with that belief that the therapist will help him control his impulse to gamble and to give up this addiction. It was his first contact with a psychotherapist and he believed that he didn't have to do anything to cure himself, and the only presence and the work of the psychotherapist would be sufficient for him to reach his objectives. He trusted only his other. Life seems difficult and dull to him, full of frustration and boredom, conflicts and problems. He felt like permanently living in a totally different world that the one he desired, which caused stress, pressure, nervousness, and which he hated and tried to "avoid".

The result of a projective test was interesting, the client drawing an ocean (his static life) and he walking on water, like Jesus, with his back turned to the watcher.

He was not aware of his gambling addiction and didn't consider himself a gambler "I only have a vice, I am not a gambles!" Gambling offers him "his space" different from the world he lives in, where he fells relaxed, "filled" with adrenaline, with well being, quiet and joy. He feels happiness only when he wins, because then he receives "rewards" for "his effort" and feels like a "winner", valued by the persons next to him, when he offers free drinks to "his friends" from his winnings and offered presents to his wife, mother, son and lovers.

This happens in rare cases, because usually he re-gambles all winnings and looses everything. He also gambles in order to recover lost sums of money. The impulse to gamble immediately and compulsively is activated by an intolerance 
to frustration, on the fund of internal and external conflicts, when he is overwhelmed by problems and responsibilities, which he doesn't assume and when he feels the need to relax, to be alone or when he gets bored.

After losing his money he is overwhelmed by guilt, by the thought that his family would leave him and rarely by suicide thought. In these cases he calls his mother or his wife to offer him comfort, not to judge, to offer affection (not rejection or reproaches) and to help him solve his new problems, created by gambling loss.

He is afraid of death and often dream about being dead and buried or that someone from the family dies. Gambling "makes me feel alive, full of adrenaline!" He believes in God and the help received. As the suggestion of his wife's and mother's, he even talked to priests and took part in rituals of "absolution" through prayers. He isn't religious, but uses non-invasive methods in the hope he will stop his addictive gambling behaviour. He waits from a solution from the outside and from others.

C.'s relation to his mother is a symbiotic one, with an insecure attachment, a combination of dependent and ambivalent. He loves and "hates" her at the same time; he respects her and considers her the most important person in his life, on which he count on, but also judges her and considered her to be the source of his problems. His mother missing his young childhood left him with a feeling of being abandoned, because he was "bad" as his grandmother used to say. He was also "abandoned" by his father, who he left down and who he wasn't capable of "wining" and "only disgraced him".

The relation with his biological father was inexistent, until the age of 5, while they were together, but the client believed it was a good, beautiful and trustful relation (he didn't remember much). The only "scene" he hasn't forgot was when his biological father took him gambling and let him throw the dice, later being quarrelled and criticised in front of other gamblers because he lost due to his lack of knowledge and luck. The punishment was to gather all cigarette butts from the ground. He remembers that he used these to pretend he smoked "like dad".

The relation with his step father and his smaller brother (T.) was "flat, empty and cold", being at the same level since the beginning, not good, not bad, practically inexistent. They just tolerated each other, without any conflicts, without problems, feelings or hard feelings and a lack of shared affection.

Relations with grandparents were different: the grandmother was a sever, aggressive, intolerant, cold, distant "dictator", who raised him with reproaches, criticism and punishment, physical and emotional abuses ("you should have died at birth, you jinx") because he hated the boy (you look exactly like your miserable father"). The grandfather was "kind and patient", offered caresses when the grandmother was missing, because he was also quarrelled by the grandmother. But he was mostly absent because he worked.

The relation with the wife was dysfunction. She loved him, understands and tolerates his vices, tries to help and be close to him, help him "grow up", but he doesn't have enough room, because of her "mother-in-law", who is constantly trying to control their lives and is jealous on her daughter-inlaw who "took her place". The two women are always in conflict, C. cares for both (in his way). And they "catch him in the middle" and each try to have him on their side. C. has "two" mothers who constantly stress him and he is a "rebel child" when he gambles or "an adopted child" when he conforms.

The relation with the son is inexistent. He doesn't know how to play the "father's role" lacking clear models and because he is still a child. The son fears his father who he considers aggressive, even if the client never manifested physical aggressiveness, only hard words, authoritarian and high volume of the voice, when the boy skipped some limits (behavioural or verbal). The child is an major dependence relation, symbiotic with his mother (the client's wife) and this relation seems to be sufficient, being "closed" in developing a relation with the father.

The only good relation is with the paternal uncle (the father's biological brother, who is also a "gambler") and who accompanies fishing, or to have a beer, to whom he communicates and with whom he feels well. With "gambler friends" the client has vague relations based on reciprocal interest.

Since his adolescent years and after being married, C. had sporadic and short sexual relations, without affectiveemotional involvement, with females that attract him. He sustains he had a physiological need (his wife having some gynaecologic problems which she postponed and didn't solve), thus he felt the need to satisfy his "man" desires, to play the role of an "adult", a role manifested only at work or in relations to strangers.

C. felt the therapist as being "human", supportive, impartial, understanding, and open, didn't feel judged, but listened to carefully and attentively and a good alliance was created on the bases of which his "story" could be presented. His therapy lasted for a long time: 40 sessions.

The client was asked for permission to note down his story, and this made him feel valued from the exterior and started a development of self-esteem (which is low after years of pathological gambling). The problems observed were many, and the collaboration of the family and the mother's was demanded.

The clients games seemed to be an unconscious manner of maintaining "the dead alive", the biological father "alive" through him, continuing his practice in a continuous trial to prove his father that he strives to meet his expectations, of being "capable", and "not embarrass him", "be lucky".

His life scenario: "walking on water!"... life lived in a imaginative manner, bizarre, unreal, irrational, and notintegrated, at chance as in gambling!

\subsection{Instruments Used in the Realisation of Psychotherapeutic Statuses}

Working instruments used in the realisation of 
psychotherapeutic statuses and of supervision sheets according to the integrative strategic model of the self are the following [12]:

a. The case, working with the client in psychotherapy, during the 40 sessions in the office; notes taken during each session with the client:

b. A model of a psychotherapeutic status proposed in the book Supervision in integrative psychotherapy, written by Loredana-Ileana Vîşcu and Oana Maria Popescu [4];

c. Notes from each session with the client, notes regarding the phenomenological aspect of the psychotherapeutic relation and the therapist's self-analysis;

d. Other writings andinsights during and after each supervision session:

e. All the instruments that helped the therapist in the realisation of the case of C.M:

i. The diagnosis manual and statistical classification of mental disorders, $5^{\text {th }}$ edition (DSM-5) elaborated by the American Psychiatric Association, USA, necessary in the establishment of a structured diagnosis [15];

ii. The integrative strategic model of the self proposed by the two authors, specific for the integrative strategic psychotherapy;

iii. The psychotherapeutic interview structured according to the integrative strategic model of the self;

iv. Psycho-education;

v. Psycho-tests (personality, intelligence tests for adults and others);

vi. Projective tests (person drawing, family drawing, drawing on different themes);

vii. Cognitive restructuring and reframing techniques and methods;

viii. Techniques used in integrative strategic psychotherapy: relaxation techniques, problem solving techniques, the technique "Mourning period", hypno-analytic techniques, techniques for depression and anxiety, therapeutic metaphors techniques: "naturalist trance induction", "favourite place", "the inside child tranquillity", "personal counsellor", "relaxation and imagery for anxiety treatment";

ix. Cognitive-behavioural techniques: "empty chair technique", "role play", "progressive desensibilization".

The procedures used in the realisation of psychotherapeutic statuses were represented by the filling in of spaces with data obtained from the case C.M. regarding some specific aspects from each psychotherapy session, as demanded by the sheet presented in the works of ViscuLoredana-Ileana $[4,11,12]$.

\subsection{Initial Psychotherapeutic Status for the Case C.M}

Psychotherapist: GeamănuAnişoara.

Client (code): 1 C.M.

Date: 21.04.2017. Initial interview: 21.04.2017. Session no. 1.

\section{i. Diagnosis.}

1. Symptoms in relation to personality aspects.

Clinical image of the disorder (DSM-5): Disorders connected to substance consumption and dependencies pathological gambling (ludomania).

The client's personality features: introversion, moments of reality detachment, lack of self trust, immaturity, and nervousness.

Identifiable symptoms: improper posture for his age and situation, restless, emotionally detached, a bit voluble, he presents discomfort in his relational and verbal interaction.

Symptoms severity:(serious) severe: 8 of the 9 diagnostic criteria from DSM-5.

Somatisation: accentuates tiredness, persistent head ache, insomnia, nervousness.

Personal resources: curiousness; social resources: communication with the family (mother, wife); environment resources:

2. Process diagnosis.

a. For the first therapeutic session. Diagnosis on the axes A, B, C, E, F, P:

Axis A: insecure attachment, type preoccupied/dependentambivalent, significant difficulties in expressing emotions, nervousness.

Axis B: inexpressive face expression, slightly bent body posture, repressed emotion, genetic vulnerability.

Axis C: maladaptive-negative thoughts ("I am not addictive, I only have a vice"), slightly infantile thinking, irrational believes, maladaptative addictive behaviour, autosabotage, low self esteem.

Axis E: he doesn't a well established purpose in life, nonrealist expectations regarding the future ("I will certainly win and get rich"), is afraid of death.

Axis F: multiple family roles, different family conflict, diffuse family borders.

Axis P: fluctuant state of the self: of "not adapted/ negative child" (rebellious, manipulative, liar); conflictsubpersonalities (sustaining addiction).

Establishment of therapeutic objectives together with the client:

1. Becoming aware and accepting problems;

2. Gaining a secure, adaptative attachment;

3. Experiencing emotional expression and ventilating repressed emotions;

4. Increase of self esteem and strengthening the self;

5. Giving up gambling by changing;

6. A normal, functionalwell being in all domains of his life, efficient inter-relating.

b. For the next therapy session. Therapeutic objectives for the 6 axes and the approach of the self (basal (BS), central (CS), plastic (PS), external (ES)) for each axis:

Axis A: the re-establishment of a secure type attachment (BS) and the identification and expression of repressed emotions (CS/ES).

Axis B: work with repressed emotions under the 
attachment influence (CS/ES) and the identification of the stress level and of its management method for the client (CS/ $\mathrm{PS} / \mathrm{ES}$ ).

Axis $C$ : the restructuring of cognitive schema (CS), the restructuring of the "here and now" thinking (ES), the identification of mechanisms of the type "if...then" (PS) and work with these mechanisms and the restructuring of cognitions regarding the self-sabotage (addictive) behaviour (PS), correlation with Axis P.

Axis E: identifying his life purpose and life meaning (CS/ ES), cognitive restructuring regarding the future.

Axis F: being aware of maladaptative family roles and getting away from those roles and understanding and solving family conflicts, of dysfunctional relations between its members (ES).

Axis P: working with the strengthening of the Self; working with the functional states of the self, with choice, experiencing, the expressing of the "adult" state, replacing the "child" state (CS/ ES) and the identification of executive subpersonalities responsible for the pathological gambling addiction (ES) and of the manner in which these become executive (PS).

ii. Recommendations for this psychotherapeutic treatment.

1. Supplementary recommendations and examinations: somatic: it is not the case; psychiatric: it is not the case; clinical: it is not the case; hospitalisation: it is not the case.

2. Recommendations for psychotherapy: emergency: it is not the case; estimated duration of the psychotherapeutic treatment: minimum 35 sessions; frequency per week: 1-2 sessions/week; psychotherapy type: individual and family counselling; psychotherapy financing: the client's mother/wife (sustainment persons).

iii. Psychotherapeutic intervention.

1. Session description:

a. Axisor waxes worked on: the establishment of a diagnosis on axes.

b. Objectives proposed on axes for this session: initial interview, the establishment of therapeutic objectives on axes.

c. Methods and techniques used to reach objectives proposed: interview with the client's mother, in order to obtain data on the client (10 minutes) and active observation, initial interview with the client; diagnosis on axes; the establishment of therapeutic objectives together with the client.

2. Description of the client's behaviour:

The client behaviour when arriving at the office: he is overwhelmed by problems, restless, nervous, state of discomfort, and a shame feeling, distant, absent, almost uncommunicative, but curious.

The identification of moment of a maximum emotional charge for the client: gestures of calming down: check rub, caress of the head with his hands, covering his arms and protecting his dead from possible hits, hand rub and feet rub, massage of fists and chewing his nails, face redness, wet eyes, low voice tone, weak voice.

Description of the client's insight (if these situations were observed): he became aware of his role of "rebel/ adapted child" exercised in close relations; he realized his addiction to pathological gambling as being connected to himself (a possible depression) and with aspects connected to the past and the present.

Changes in the client's behaviours: his restlessness, nervousness and agitation was gradually replaced by a state of progressive calmness, by the activation of hope (expressed on his face), the manifest of curiousness and interest (begins to ask questions), communicates in his rhythm, takes long breaks and thinks before speaking, is open towards a therapeutic alliance.

Homework (if it is the case) and the encouragement of behavioural changes in the client:

a. Start a personal diary where he can present in detail and in writing, the detail history of his pathological gambling: start periods, dependence evolution, factors which determined this evolution, sums of money lost, negative consequences felt etc.;

b. He was insured that there was nothing wrong with him, if he was a gambler he will assume this!and if "all people can change" he is the only one who can decide, thus assuming responsibility for his healing through involvement! He will constantly receive support for his actions to change.

3. Description of the therapeutic relation for this session:

The therapist's reflection on the manner in which he build the therapeutic alliance (for the first session): the therapist received the client's accept, congruence; he was contained in his moments of emotional tensions, he received empathy (with afferent limits); he was offered support and understanding; he was listened to attentively, calmly and patiently. He was encouraged to communicate and get involved. A therapeutic alliance was built during the second half of the session, based on the development of a good therapeutic relation.

Possible moment of relation "rupture", when did these appear? How was the relation repaired? This was not the case.

How did the therapist perceive the client in therapy, what feelings of comfort, somatic discomfort, somnolence, difficulties in attention, irritation, the desire to end the session rapidly, the perception of time etc.? Initially communication was difficult, a lot of patience, tact and presence of spirit were necessary. Discomfort was felt and a slight state of tiredness, because it demanded maximum concentration from the therapist in order to follow the client, to obtain a continuity in ideas, because the client skipped from one idea to another or made long pauses, unproductive. Time felt difficult to perceive.

The client's needs, his style of attachment manifested in the therapeutic relation: the attachment style perceived was the insecure one, preoccupied/dependent-ambivalent. 
The need to be listened and not be judged, the need to be accepted, understood, the need for support and help were underlined.

The therapist's proposals for the improvement of the therapeutic relation: more understanding, congruence, containment, making the client feel understood, safe, trustful and involved in equal measure, responsible for the therapeutic relation.

\section{Conclusions}

The practical exemplification of the initial status of the case exposed was meant to launch a challenge offered to the readers of this paper, to continuously develop their professional competencies.

By completing all steps necessary in the realization of psychotherapeutic statuses for the case C.M. and of the present paper, fears were confronted, remains of performance anxiety, which become conscious, controlled, correctly and productively managed in order to be over passed and to obtain a general state of well being. These helped in a better understanding of aspects contained in the case, in the initial phase, in the planning of a personal working demarche as psychotherapist and which helped in becoming aware of the usefulness of this status in the facilitating of office work and in the presentation of cases during supervision.

By extrapolating, one has the conviction that this can also help colleagues in supervision and that understanding will be easily accessed, thus reaching the objectives proposed in the writing of this paper. The "lesson" proposed may be useful in the practical example of filled statuses, by diminishing any "anxieties" of professional novices, in gaining correct management abilities of a case.

This paper may also help in the activation of internal resources, in contradicting or adding to the personal manner in which the case was exposed. How?! Through new manners to approach the problems contained in the status, according to the development level of each therapist and with the proper value system.

The presentation of a concrete therapeutic case, of the elements of a psychotherapeutic status, for the first therapy session, may clarify the simple structure and the demarche needed to fill in any status. It may also represent a "stimulus" material for self-evaluation and/or self-reflection for each psychotherapist interested.

\section{References}

[1] Popescu, O. M., Viscu, L. I., (2016). Psihoterapie integrativă strategică. Teorie ş iaplicaţii practice. Craiova: Liber Mundi.

[2] Viscu, L. I., Popescu, O. M., (2015). Abordări în psihoterapia integrativă strategică. Resita, Romania: Publibanat.

[3] Drobot, L. I., Popescu, O. M., (2013). Manual de psihoterapie integrativă. Bucharest, Romania: Didactic and pedagogic publishing house.

[4] Viscu, L. I., Popescu, O. M., (2017). Supervizarea în psihoterapia integrativă strategică. Iasi, Romania: Junimea.

[5] Viscu L.-I., Popescu O.-M., (2017). An existential approach of the future psychotherapist's concerns. Proceedings 24th International symposium of research and applications in psychology, SICAP: Cognitive characteristics of transdisciplinary applications in psychology and psychotherapy. Vol. ISBN: 978-88-95922-85-0, pages. 294299, WOS: 000406423100041, www.webofknowledge.com.

[6] Viscu, L. I; Popescu, O. M.; Morosoi, V., (2016). Diagnostic: label or landmark in the development of the patients' potential?. Conference: 23rd International Symposium on Theoretical and Applied in Psychology (SICAP23) Psychology and Ongoing Development, Timisoara, Romania, 20-21 Nov, 2015, Proceedings 23rd International Symposium on Theoretical and Applied in Psychology (SICAP23) Psychology and Ongoing Development pages. 195-200, ISBN: 978-88-7587-735-4, WOS: 000391521400038, www.webofknowledge.com.

[7] Wampold, B. E. (2007). Psychotherapy: The humanistic (and effective) treatment. American Psychologist, 62, 857-873.

[8] Popescu O. M. \& Viscu L.-I. (2017). Factorii comuni în psihoterapie. O abordare integrativ-strategică, Bucharest: Pro Universitaria Publishing House.

[9] Lacrama L. D., Viscu L.-I. (2017). Biological neuronal networks base for artificial neural nets, Proceedings 24th International symposium of research and applications in psychology, SICAP: Cognitive characteristics of transdisciplinary applications in psychology and psychotherapy. Vol. ISBN: 978-88-95922-85-0, pages. 106115, WOS: 000406423100016, www.webofknowledge.com.

[10] Popescu, O. M., Drobot, L., (2016). Integrative Strategic Psychotherapy-the Four-Self Model, Proceedings 23rd International Symposium on Theoretical and Applied in Psychology (SICAP23) - Psychology and Ongoing Development, pages. 243-148, ISBN: 978-88-7587-735-4, WOS: 000391521400028, www.webofknowledge.com.

[11] Vîşcu L.-I. (2018). Modelul integrativ strategic de supervizare, Bucharest: Academic Universe Publishing House.

[12] Vîşcu L.-I. (2018). Supervizarea în psihoterapie. Instrumentele terapeutului supervizat, Bucharest: Academic Universe Publishing House.

[13] Watkins CE Jr. (2018) The Supervision Pyramid: A Commonalities-Based Synthesis of Intervention, Relationship, and Person/Personhood. Am J Psychother. 2018 Nov 1; 71 (3): 88-94. doi: 10.1176/appi.psychotherapy.20180017. Epub 2018 Aug 15.

[14] Watkins, C. E., Jr. (2017). How does psychotherapy supervision work? Contributions of connection, conception, allegiance, alignment, and action. Journal of Psychotherapy Integration, 27, 201-217.

[15] American Psychiatric Association, (2016) DSM - V - Manual de Diagnostic şi Statistică a Tulburărilor Mentale, 5th edition. Bucharest: Callisto Medical Publishing House. 